\title{
AP2/ERF Family Transcription Factors ORA59 and RAP2.3 Interact in the Nucleus and Function Together in Ethylene Responses
}

\author{
Na Young Kim, Young Jin Jang and Ohkmae K. Park* \\ Department of Life Sciences, Korea University, Seoul, South Korea
}

The gaseous plant hormone ethylene is a key signaling molecule regulating plant growth, development, and defense against pathogens. Octadecanoid-responsive arabidopsis 59 (ORA59) is an ethylene response factor (ERF) transcription factor and has been suggested to integrate ethylene and jasmonic acid signaling and regulate resistance to necrotrophic pathogens. Here we screened for ORA59 interactors using the yeast twohybrid system to elucidate the molecular function of ORA59. This led to the identification of RELATED TO AP2.3 (RAP2.3), another ERF transcription factor belonging to the group VII ERF family. In binding assays, ORA59 and RAP2.3 interacted in the nucleus

OPEN ACCESS

Edited by:

Jens Staal,

Ghent University, Belgium

Reviewed by:

Silvia Proietti,

Università degli Studi della Tuscia, Italy

Jorge Vicente,

University of Nottingham,

United Kingdom

${ }^{*}$ Correspondence:

Ohkmae K. Park

omkim@korea.ac.kr

Specialty section:

This article was submitted to

Plant Microbe Interactions,

a section of the journal

Frontiers in Plant Science

Received: 11 September 2018

Accepted: 26 October 2018

Published: 19 November 2018

Citation:

Kim NY, Jang YJ and Park OK (2018) AP2/ERF Family Transcription Factors ORA59 and RAP2.3 Interact in the Nucleus and Function Together

in Ethylene Responses.

Front. Plant Sci. 9:1675.

doi: 10.3389/fp/s.2018.01675 and showed ethylene-dependent nuclear localization. ORA59 played a positive role in ethylene-regulated responses, including the triple response, featured by short, thick hypocotyl and root, and exaggerated apical hook in dark-grown seedlings, and resistance to the necrotrophic pathogen Pectobacterium carotovorum, as shown by the increased and decreased ethylene sensitivity and disease resistance in ORA59overexpressing (ORA59OE) and null mutant (ora59) plants, respectively. In genetic crosses, ORA59OE rap2.3 crossed lines lost ORA59-mediated positive effects and behaved like rap2.3 mutant. These results suggest that ORA59 physically interacts with RAP2.3 and that this interaction is important for the regulatory roles of ORA59 in ethylene responses.

\footnotetext{
Keywords: Arabidopsis thaliana, ORA59, RAP2.3, ethylene response factor, ethylene, Pectobacterium carotovorum, disease resistance, plant immunity
}

\section{INTRODUCTION}

During evolution, plants have become equipped with defense mechanisms that enable them to survive against environmental stresses. The survival strategies of plants include the timely production of phytohormones that play key roles in regulating plant defense (Gupta et al., 2017). Salicylic acid (SA), jasmonic acid (JA), and ethylene are major hormones regulating the defense against pathogens (Glazebrook, 2005; Kwon et al., 2009; Pieterse et al., 2012). Other hormones such as abscisic acid (ABA), auxin, gibberellin (GA), cytokinin, and brassinosteroid have also been implicated in defense responses (Siemens et al., 2006; Wang et al., 2007; Asselbergh et al., 2008; Navarro et al., 2008; Shan et al., 2008). SA is generally associated with resistance to biotrophic pathogens such as Pseudomonas syringae and Hyaloperonospora arabidopsidis, whereas JA and ethylene trigger resistance to necrotrophic pathogens such as Alternaria brassicicola and Botrytis cinerea (Pieterse et al., 1996; 
Penninckx et al., 1998; Glazebrook, 2005). Hormones or signaling molecules function through signaling pathways that are interconnected to form a complex network. Numerous reports have described both antagonistic and synergistic interactions between SA and JA/ethylene pathways (Kunkel and Brooks, 2002; Spoel and Dong, 2008). Whereas ethylene and JA signaling often interact synergistically, there is antagonism between SA and JA/ethylene (Penninckx et al., 1998; Thomma et al., 1998; Koornneef et al., 2008; Kim et al., 2013). This may be the outcome of evolution towards reducing the fitness cost, enabling plants to prioritize either the SA or JA/ethylene pathway depending on the lifestyle of invading pathogens.

The gaseous hormone ethylene plays pivotal roles in plant growth, development, and stress responses (Wang et al., 2002; van Loon et al., 2006; Cho and Yoo, 2009). Ethylene initiates a signaling cascade when bound to ethylene receptor family members in the endoplasmic reticulum (ER): ethylene resistance 1 (ETR1), ETR2, ethylene insensitive 4 (EIN4), ethylene response sensor 1 (ERS1), and ERS2 in Arabidopsis (Chang et al., 1993; Hua and Meyerowitz, 1998; Hua et al., 1998; Sakai et al., 1998). In the absence of ethylene, ethylene receptors act as negative regulators and activate constitutive triple response 1 (CTR1), a Raf-like serine/threonine kinase that phosphorylates an ERlocated membrane protein EIN2 to repress ethylene signaling (Kieber et al., 1993). The presence of ethylene switches off CTR1, leading to activation of positive regulators EIN2 and EIN3 (Chao et al., 1997). EIN2 is cleaved, releasing the C-terminal fragment, which moves to the nucleus and stabilizes EIN3 and EIN3like 1 (EIL1) by downregulating EIN3-binding F-box protein 1 (EBF1) and EBF2 required for EIN3/EIL1 degradation (Guo and Ecker, 2003; Potuschak et al., 2003; Gagne et al., 2004; Ju et al., 2012; Qiao et al., 2012; Wen et al., 2012). EIN3 and EIL1 further regulate the expression of the ethylene response factor (ERF) family transcription factors, belonging to the APETALA2 (AP2)/ERF superfamily (Solano et al., 1998).

Many reports have demonstrated the importance of ERFs in crosstalk among ethylene, JA, and SA for regulating disease resistance (Caarls et al., 2017). ERF1 and octadecanoidresponsive arabidopsis 59 (ORA59) belong to the group IX ERF family and have been suggested to act as integrators of ethylene and JA pathways (Lorenzo et al., 2003; Pré et al., 2008). The expression of JA/ethylene-responsive pathogenesisrelated genes plant defensin 1.2 (PDF1.2) and basic chitinase (b$\mathrm{CHI}$ ) was induced synergistically by JA and ethylene, depending on ERF1 and ORA59 (Pré et al., 2008). In binding analyses, ERF1 and ORA59 directly bound to GCC boxes in the PDF1.2 promoter, resulting in a synergistic response to JA and ethylene (Zarei et al., 2011). ERF1 and ORA59 themselves were also activated by JA and ethylene in a synergistic manner. This JA/ethylene-dependent expression was abolished in JAinsensitive coronatine insensitive 1 (coi1) or ethylene-insensitive ein2 mutants (Penninckx et al., 1998; Lorenzo et al., 2003; Pré et al., 2008). Overexpression of ERF1 and ORA59 enhanced resistance to necrotrophic pathogens such as Botrytis cinerea, indicating that ERF1 and ORA59 are major components in JA/ethylene-regulated defense responses (Berrocal-Lobo et al., 2002; Pré et al., 2008). Additionally, ORA59 has been evaluated as a target of SA-mediated antagonism of JA signaling (Van der Does et al., 2013). SA suppressed JA-responsive gene expression by downregulating ORA59 accumulation. In agreement with this, ORA59 overexpression in plants counteracted the SA-mediated antagonistic effect on JA-mediated PDF1.2 expression (LeonReyes et al., 2010; Van der Does et al., 2013; He et al., 2017).

Here an ERF family transcription factor, related to AP2.3 (RAP2.3), was identified as an ORA59-interacting protein by yeast two-hybrid $(\mathrm{Y} 2 \mathrm{H})$ screening. We examined the interactions and functions of ORA59 and RAP2.3 in response to ethylene. ORA59 positively regulated the ethylene-triggered triple response and resistance to the necrotrophic pathogen Pectobacterium carotovorum (also called Erwinia carotovora), which depended on RAP2.3. These results suggest that ORA59 interacts with RAP2.3 to regulate ethylene-dependent responses.

\section{MATERIALS AND METHODS}

\section{Plant Materials and Growth Conditions}

Arabidopsis thaliana (ecotype Columbia, Col-0) plants were grown at $23^{\circ} \mathrm{C}$ under long-day conditions (16-h light/8-h dark cycle) for general growth and under short-day conditions (8$\mathrm{h}$ light/16-h dark cycle) for pathogen infection and hormone treatments. The following plant lines were used in this study: ein2-1 (Yoo et al., 2008), ein3-1 eil1-1 (Alonso et al., 2003), EIN3OE (Chao et al., 1997), rap2.3-2 (Marín-de la Rosa et al., 2014), and erfVII (Marín-de la Rosa et al., 2014). ora591 (GABI_CS405772) and TPT_RAP2.3 (GK-210F05.02) lines were obtained from the Arabidopsis Biological Resource Center (Columbus, OH, United States) and Nottingham Arabidopsis Stock Centre (Nottingham, United Kingdom), respectively. To generate ORA59OE plants, the full-length cDNA of ORA59 was amplified and cloned into the binary vector pCAMBIA1300 under the control of the cauliflower mosaic virus (CaMV) $35 \mathrm{~S}$ promoter. The construct was transformed into Arabidopsis plants using the floral dip method (Clough and Bent, 1998). Transformants were selected on $1 / 2$ MS media containing $10 \mu \mathrm{g} / \mathrm{mL}$ hygromycin and homozygous T3 seeds were used for experiments. ORA59OE and ora59-1 lines were crossed with rap2.3-2 and erfVII mutants, and homozygous lines were confirmed by PCR and sequence analysis using gene-specific primers (Supplementary Table S1).

\section{Plant Treatments}

For pathogen infection, 4-week-old plants grown under shortday conditions were used (Lee et al., 2017). P. carotovorum was cultured in L-medium containing $100 \mu \mathrm{g} / \mathrm{mL}$ ampicillin at $28^{\circ} \mathrm{C}$ for 1 day. Leaves were infiltrated with $10 \mu \mathrm{L}$ of $\mathrm{NaCl}(0.9 \%)$ or a bacterial suspension $\left(10^{4}-10^{5} \mathrm{cfu} / \mathrm{mL}\right)$ and incubated for 1 day before analysis of disease development and gene expression. For hormone treatments, 4-week-old plants grown under short-day conditions were sprayed with ethephon (ET; $1.5 \mathrm{mM})$, salicylic acid (SA; $1 \mathrm{mM}$ ), methyl jasmonate (MeJA; $50 \mu \mathrm{M})$, abscisic acid $(\mathrm{ABA} ; 10 \mu \mathrm{M})$, and gibberellin $(\mathrm{GA} ; 10 \mu \mathrm{M})$ dissolved in $0.1 \%(\mathrm{v} / \mathrm{v})$ dimethyl sulfoxide (DMSO). The treated plants were maintained at $100 \%$ humidity for the indicated times. 


\section{Phenotypic Analysis of Etiolated Seedlings}

Phenotypes of 1-aminocyclopropane-carboxylic acid (ACC)treated etiolated seedlings, the so-called triple response, were analyzed as previously described (Yoo et al., 2008). Sterilized seeds were plated on $1 / 2$ MS media containing $1 \%$ sucrose alone or supplemented with $10 \mu \mathrm{M}$ ACC. For $p E R 8$ and TPT_RAP2.3 lines, media was additionally supplemented with $5 \mu \mathrm{M} \beta$-estradiol. Plates were wrapped in foil to maintain the dark conditions and kept for 4 days at $23^{\circ} \mathrm{C}$.

\section{Yeast Two-Hybrid Screening}

Total RNAs were isolated from 6-week-old Col-0 plants treated with $1.5 \mathrm{mM}$ ethephon for $24 \mathrm{~h}$ and used to construct a Mate \& Plate ${ }^{\mathrm{TM}}$ library in accordance with the protocol of the Matchmaker ${ }^{\text {TM }}$ Gold Yeast Two-Hybrid System (CLONTECH, Mountain View, CA, United States). Y2H screening was performed according to the manufacturer's instructions. To test for the interaction of ORA59 with RAP2.3, ORA59 and RAP2.3 were cloned into the pGADT7 and pGBKT7 vectors (CLONTECH). The yeast strain AH109 was co-transformed with the constructs, grown on synthetic dextrose (SD)/-LeuTrp media, and then transferred to SD/-Ade-His-Leu-Trp media. Transactivation activity was further evaluated based on the activity of $\alpha$-galactosidase on SD/-Ade-His-Leu-Trp media containing $40 \mathrm{mg} / \mathrm{L}$ of $\mathrm{X}-\alpha-\mathrm{Gal}$.

\section{Gene Expression Analysis}

Total RNAs were extracted from 4-week-old plants grown under short-day conditions using TRIsure reagent (BIOLINE, London, United Kingdom) and used to synthesize first-strand cDNAs with a PrimeScript ${ }^{\text {TM }}$ RT reagent Kit (TAKARA, Shiga, Japan). Quantitative real-time PCR was performed using KAPA SYBR FAST qPCR master mix (KAPA Biosystems, Wilmington, MA, United States) with gene-specific primers (Supplementary Table S1) on a LightCycler 480 system (ROCHE, Basel, Switzerland) according to the manufacturer's protocol. The expression of tested genes was normalized to the constitutive expression level of ACTIN1 and calculated using the LinRegPCR software (Heart Failure Research Center). Experiments were repeated at least three times with biologically independent samples.

\section{GST Pull-Down Assay}

ORA59 and RAP2.3 were tagged with glutathione $S$-transferase (GST) or His at the C-terminus and recombinant proteins were affinity-purified with glutathione sepharose $4 \mathrm{~B}$ beads (GE Healthcare, Little Chalfont, United Kingdom) or Ni-NTA chelating agarose CL-6B (PEPTRON, Daejeon, Korea), according to the manufacturer's instructions. A pull-down assay was performed as previously described (Lee et al., 2017), with some modifications. GST- or ORA59-GST $(10 \mu \mathrm{g})$ was incubated with glutathione sepharose $4 \mathrm{~B}$ beads for $2 \mathrm{~h}$ in binding buffer (25 mM Tris- $\mathrm{HCl}, \mathrm{pH} 8.0,100 \mathrm{mM} \mathrm{NaCl}, 1 \%$ Triton X-100, and $1 \mathrm{mM}$ DTT $)$ at $4^{\circ} \mathrm{C}$. RAP2.3-His $(10 \mu \mathrm{g})$ was added and reacted for $2 \mathrm{~h}$ at $4^{\circ} \mathrm{C}$. Bound proteins were eluted by boiling in $6 \times$ SDS loading buffer (350 mM Tris- $\mathrm{HCl}, \mathrm{pH} 6.8,10 \%$ SDS, 30\% glycerol, $5 \% \beta$-mercaptoethanol, and $0.02 \%$ bromophenol blue), separated by SDS-PAGE, and visualized by immunoblotting using anti-GST and anti-His antibodies (SANTA CRUZ, Dallas, TX, United States).

\section{BiFC and Subcellular Localization}

For BiFC, bZIP63, ORA59, and RAP2.3 were cloned into the pUC-SPYNE and pUC-SPYCE vectors for the expression of fusion proteins bZIP63-SPYNE, bZIP63-SPYCE, ORA59SPYNE, and RAP2.3-SPYCE. For subcellular localization, ORA59 and RAP2.3 were cloned into the pUC-GFP and pUC-RFP vectors for the expression of fusion proteins ORA59-GFP, RAP2.3-GFP, and RAP2.3-RFP. GFP, RFP, and split YFP (SPYNE and SPYCE) were fused to the C-terminus of ORA59 and RAP2.3. The pUC-NLS-RFP vector was used for a nuclear marker. Arabidopsis protoplasts were transfected with these constructs and incubated for 20-24 $\mathrm{h}$ for protein expression and then treated with $0.1 \%$ DMSO (mock) or $1.5 \mathrm{mM}$ ET for $4 \mathrm{~h}$. Fluorescence signals were visualized using a confocal microscope (LSM 700; ZEISS, Oberkochen, Germany).

\section{Trypan Blue Staining}

Trypan blue staining was performed as previously described (Bowling et al., 1997). Leaves were immersed in lactophenol blue solution (Sigma-Aldrich, St. Louis, United States) and reacted for overnight. Stained leaves were placed in a $60 \%$ chloral hydrate solution and finally equilibrated with $50 \%$ glycerol.

TABLE 1 | Potential ORA59 interactors identified in the Y2H screen.

\begin{tabular}{|c|c|c|}
\hline AGI code & Gene name & Description \\
\hline AT5G42100 & BG_PPAP & $\begin{array}{l}\beta \text {-1,3-glucanase, plasmodesmal } \\
(\mathrm{Pd}) \text {-associated membrane protein involved in } \\
\text { plasmodesmal callose degradation }\end{array}$ \\
\hline AT5G51880 & & $\begin{array}{l}\text { 2-oxoglutarate (2OG) and Fe (II)-dependent } \\
\text { oxygenase superfamily protein }\end{array}$ \\
\hline AT1G08520 & ALB1 & $\begin{array}{l}\text { CHLD subunit of the Mg-chelatase enzyme } \\
\text { involved in chlorophyll biosynthesis }\end{array}$ \\
\hline AT1G68010 & HPR & Hydroxypyruvate reductase \\
\hline AT3G12780 & PGK1 & Phosphoglycerate kinase 1 \\
\hline AT3G16770 & RAP2.3 & $\begin{array}{l}\text { Member of the ethylene response factor (ERF) } \\
\text { subfamily B-2 of the plant specific ERF/AP2 } \\
\text { transcription factor family }\end{array}$ \\
\hline AT5G58070 & $\mathrm{TIL}$ & Temperature-induced lipocalin TIL 1 \\
\hline AT4G05320 & UBQ10 & $\begin{array}{l}\text { Polyubiquitin } 10 \text {, the highly conserved } \\
76 \text {-amino acid protein ubiquitin that is } \\
\text { covalently attached to substrate proteins } \\
\text { targeting most for degradation }\end{array}$ \\
\hline AT3G26520 & TIP2 & Gamma tonoplast intrinsic protein 2 \\
\hline AT5G16050 & GRF5 & $\begin{array}{l}\text { General regulatory factor } 5 \text {, GF14 upsilon } \\
\text { chain, a 14-3-3 gene family member }\end{array}$ \\
\hline AT2G41100 & $\mathrm{TCH} 3$ & $\begin{array}{l}\text { Calmodulin-like protein, with six potential } \\
\text { calcium binding domains }\end{array}$ \\
\hline AT2G30950 & VAR2 & $\begin{array}{l}\text { FtsH extracellular protease family, } \\
\text { metalloprotease that functions in thylakoid } \\
\text { membrane biogenesis }\end{array}$ \\
\hline
\end{tabular}


A

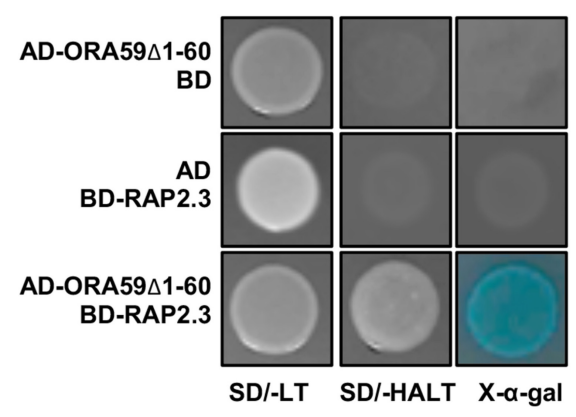

B
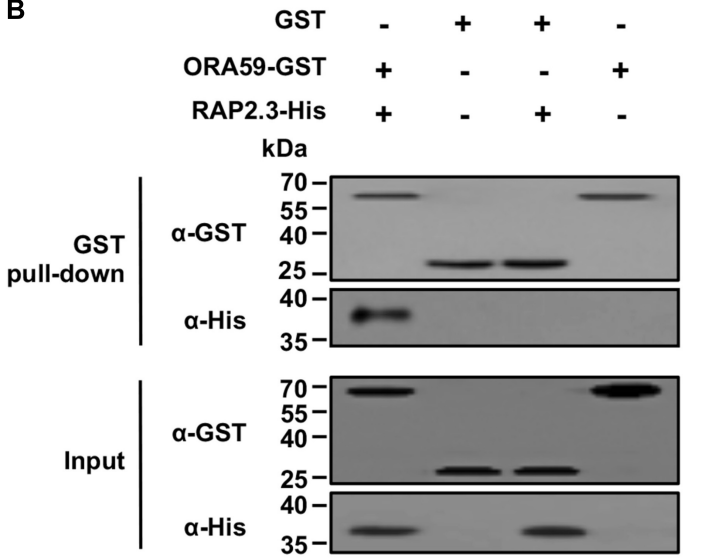

C

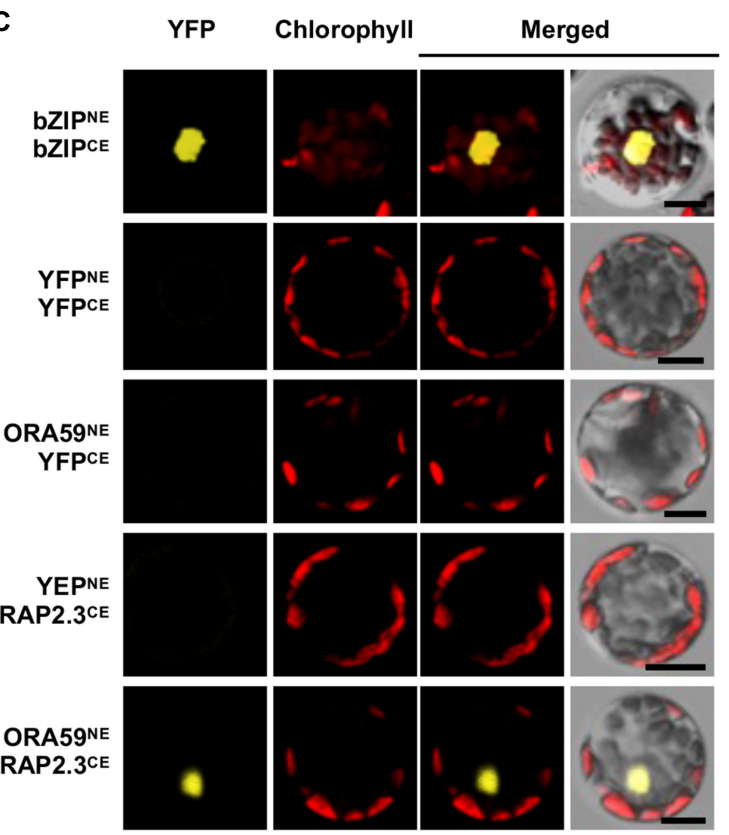

FIGURE 1 | Physical interaction of ORA59 with RAP2.3. (A) Yeast two-hybrid assay. ORA59 with N-terminal 60 amino acids deleted (ORA59 1 -60) and full-length RAP2.3 were fused with GAL4 AD and BD, respectively. Their interactions were tested on selective media SD/-AHLT and in the presence of X- $\alpha$-Gal. (B) In vitro GST pull-down assay. GST or ORA59-GST was incubated with RAP2.3-His and precipitated with glutathione sepharose 4B beads. Proteins were detected by immunoblotting with anti-GST and anti-His antibodies. Input shows $1 \%$ of the amount used in binding reactions. WB, western blotting. (C) BiFC assay. YFPNE, YFPCE , and their fusion proteins bZIP63 ${ }^{\mathrm{NE}}$, bZIP63 ${ }^{\mathrm{CE}}$, ORA59 ${ }^{\mathrm{NE}}$, and RAP2.3 ${ }^{\mathrm{CE}}$ were expressed in Arabidopsis protoplasts as indicated. YFP fluorescence signals were visualized under a confocal microscope. Bars, $10 \mu \mathrm{m}$. Experiments were repeated three times with similar results.

\section{RESULTS}

\section{ORA59 Physically Interacts With RAP2.3}

To identify proteins that interact with ORA59, we performed $\mathrm{Y} 2 \mathrm{H}$ screening using a cDNA library prepared from ethephontreated Arabidopsis plants. Full-length ORA59 was fused to the GAL4 activation domain (AD) and tested for autoactivation before screening. Yeast cells transformed with the AD-ORA59 construct alone grew on selective media lacking adenine, histidine, leucine, and tryptophan (SD/-AHLT), indicating that ORA59 can autoactivate the reporter gene (Supplementary Figure S1). To prevent autoactivation, we made truncations at the $\mathrm{N}$ - or C-terminal regions of ORA59. The truncated form of ORA59 with N-terminal 60 amino acids deleted (ORA59 $\Delta 1$ $60)$ showed no autoactivation, and therefore, was used as a bait construct. $\mathrm{Y} 2 \mathrm{H}$ screening led to the isolation of 12 proteins as potential ORA59 interactors (Table 1); among these, another ERF member RAP2.3 was chosen for further analysis.

Because the clones selected from $\mathrm{Y} 2 \mathrm{H}$ screening had partial sequences, the entire RAP2.3 CDNA was cloned and re-tested for the interaction with ORA59 in the Y2H system (Figure 1A). Coexpression of ORA59 $\Delta 1-60$ fused to the GAL4 AD and RAP2.3 to the GAL4 DNA-binding domain (BD) enabled yeast cells to grow on $\mathrm{SD} /$-AHLT media and turn blue in the presence of X- $\alpha$-Gal, indicating a direct interaction of ORA59 and RAP2.3 in yeast. We performed additional binding analyses. The in vitro interaction was verified in a GST pull-down assay using C-terminal GSTtagged ORA59 (ORA59-GST) and His-tagged RAP2.3 (RAP2.3His) recombinant proteins (Figure 1B). The in vivo interaction was assessed by bimolecular fluorescence complementation (BiFC) assays. ORA59 fused with the N-terminal part of YFP $\left(\mathrm{ORA} 59^{N E}\right)$ and RAP2.3 fused with the C-terminal part of YFP (RAP2. ${ }^{C E}$ ) were transiently expressed in Arabidopsis protoplasts. Their co-expression resulted in nuclear fluorescence signals (Figure 1C), suggesting that ORA59 interacts with RAP2.3 in the nucleus of plant cells.

\section{Expression Analysis of ORA59 and RAP2.3}

We examined the responses of ORA59 and RAP2.3 expression to hormones. For this, Col-0 plants were treated with SA, MeJA, $\mathrm{ET}, \mathrm{ABA}$, and GA. Consistent with the previous report (Pré et al., 2008), ORA59 expression was induced by MeJA, ET, and $\mathrm{SA}$, as well as by GA to a slightly lower level (Figures $\mathbf{2 A}, \mathbf{B}$ ). However, all these hormones increased the expression of RAP2.3. Basal and ET-induced expression of ORA59 and RAP2.3 was 

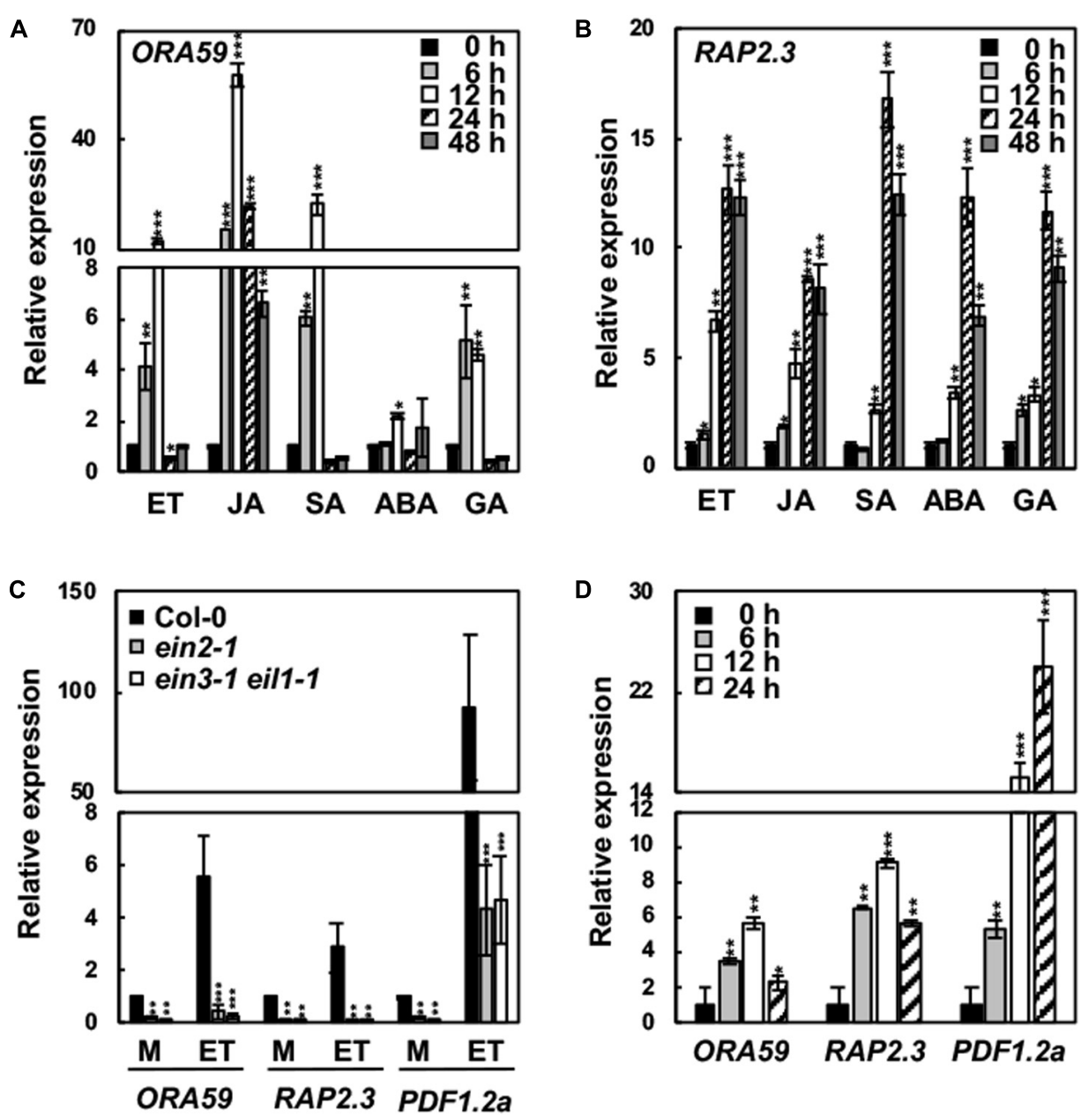

FIGURE 2 | Hormone responses of ORA59 and RAP2.3 expression. (A,B) Expression of ORA59 (A) and RAP2.3 (B) in response to hormone treatments. (C) Expression of ORA59 and RAP2.3 in ein2 and ein3 eil1 backgrounds. (D) Expression of ORA59 and RAP2.3 in response to P. carotovorum inoculation. Four-week-old plants were treated with ET (1.5 mM), MeJA (50 $\mu \mathrm{M}), \mathrm{SA}(1 \mathrm{mM}), \mathrm{ABA}(10 \mu \mathrm{M})$, or GA (10 $\mu \mathrm{M})$ for the indicated times in (A,B), with 0.1\% DMSO (mock) or ET (1.5 mM) for $6 \mathrm{~h}$ in (C), and with P. carotovorum $\left(10^{4} \mathrm{cfu} / \mathrm{mL}\right)$ for the indicated times in (D). The values represent means $\pm \mathrm{SD}$ from three independent experiments. Asterisks indicate significant differences from $0 \mathrm{~h}$ treatment $\mathbf{( A , B , D )}$ and $\mathbf{C o l}-0$ (C) $\left(t\right.$-test; $\left.{ }^{* *} P<0.01 ;{ }^{* * *} P<0.001\right)$.

largely decreased in ein2 and ein3 eil1 mutant plants (Figure 2C). These results indicate that ORA59 and RAP2.3 expression is regulated by ethylene signaling components such as EIN2 and EIN3/EIL1. We further analyzed ORA59 and RAP2.3 expression in response to pathogen infection. When inoculated with the necrotrophic bacterial pathogen $P$. carotovorum, Col-0 plants strongly expressed both ORA59 and RAP2.3 (Figure 2D), suggesting that ORA59 and RAP2.3 may function together in immune responses.

\section{Nuclear Localization of ORA59 and RAP2.3 Is Promoted by ET Treatment}

Subcellular localization of ORA59 and RAP2.3 was determined with or without ET treatment. Arabidopsis Col-0 protoplasts were transfected with GFP- or red fluorescent protein (RFP)fused ORA59 and RAP2.3 constructs. ORA59 and RAP2.3 fluorescence signals were both detected in the cytosol and nucleus, showing substantial co-localization in these compartments (Figure 3A). After ET treatment, ORA59 and RAP2.3 proteins were mostly localized to the nucleus (Figure 3B). This suggests that the transcriptional activity of ORA59 and RAP2.3 is regulated through nuclear targeting, which is regulated by ethylene signaling. However, ETdependent nuclear localization of ORA59 and RAP2.3 was not affected in rap2.3 and ora59 mutant backgrounds, respectively (Figures 3C-F), indicating that the interaction of ORA59 and RAP2.3 is not required for nuclear translocation.

\section{ORA59 Positively Affects the Triple Response in an RAP2.3-Dependent Manner}

For functional analysis, mutant and transgenic Arabidopsis lines for ORA59 and RAP2.3 were prepared. We obtained ora59-1 mutant (Supplementary Figures S2A-C) and rap2.3-2 mutant 


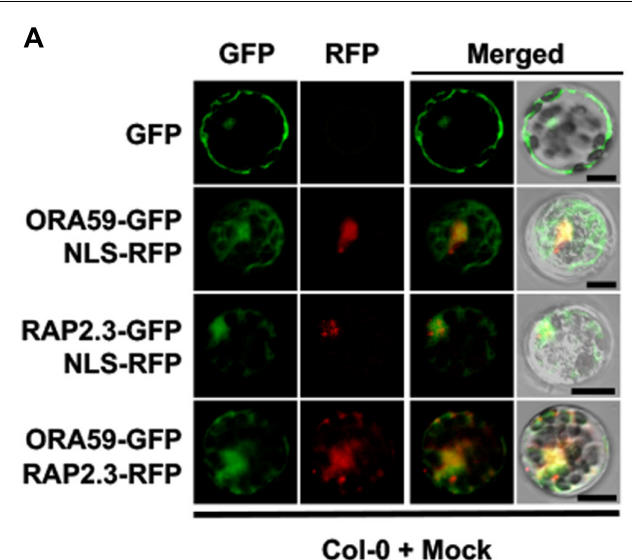

Col-0 + Mock

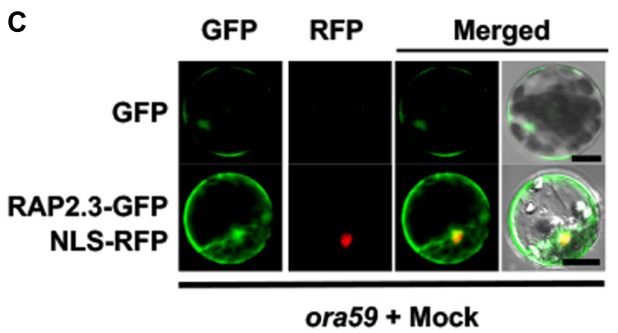

E

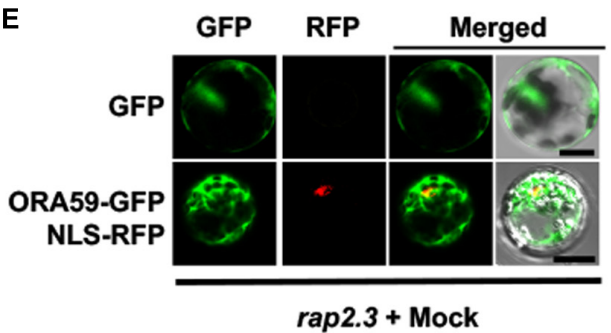

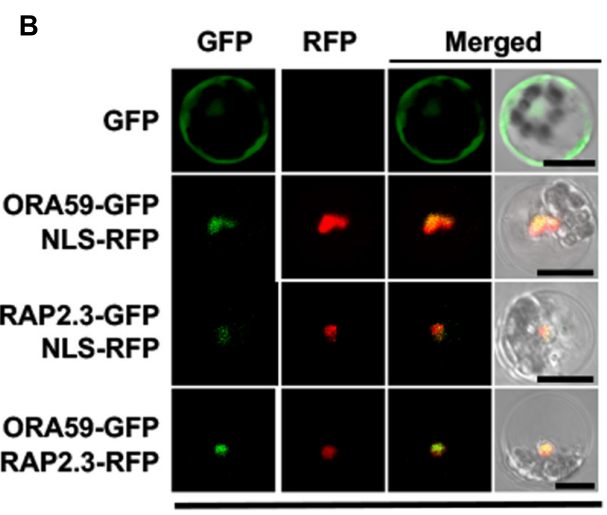

Col-0 + ET
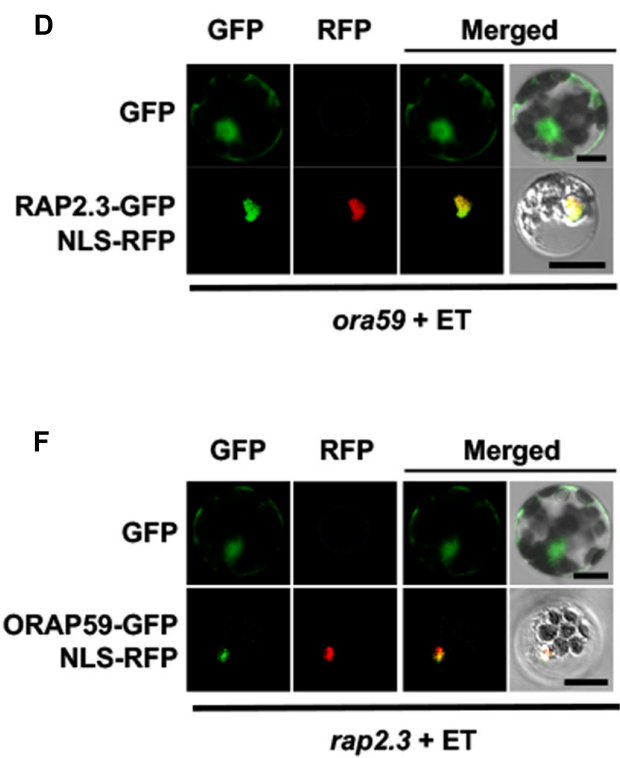

FIGURE 3 | ET-dependent nuclear co-localization of ORA59 and RAP2.3. (A,B) Subcellular localization of ORA59 and RAP2.3 in Col-0 protoplasts treated with $0.1 \%$ DMSO (mock) (A) or 1.5 mM ET (B) for 4 h. (C,D) Subcellular localization of ORA59 in rap2.3 protoplasts treated with $0.1 \%$ DMSO (mock) (C) or 1.5 mM ET (D) for 4 h. (E,F) Subcellular localization of RAP2.3 in ora59 protoplasts treated with 0.1\% DMSO (mock) (E) or 1.5 mM ET (F) for 4 h. ORA59-GFP, RAP2.3-GFP, RAP2.3-RFP, and NLS-RFP were expressed in Arabidopsis protoplasts as indicated. Fluorescence signals were visualized under a confocal microscope. Bars, $10 \mu \mathrm{m}$. Experiments were repeated three times with similar results.

(Marín-de la Rosa et al., 2014; Supplementary Figure S3A), and generated transgenic plants overexpressing ORA59 under the control of the CaMV 35S promoter (ORA59OE) (Supplementary Figure S2C). A transgenic transplanta (TPT) line conditionally overexpressing RAP2.3 under the control of the $\beta$-estradiolinducible promoter (TPT_RAP2.3) was obtained (Coego et al., 2014) and tested together with a vector control line ( $p E R 8)$ (Supplementary Figure S3A). RAP2.3 is a member of the group VII ERF family, and genetic redundancy among members [RAP2.2. RAP2.3, RAP2.12, hypoxia responsive ERF1 (HRE1), and HRE2] has been described (Marín-de la Rosa et al., 2014). Therefore, a quintuple mutant defective in all five members, erfVII, was additionally included in the analysis (Marín-de la Rosa et al., 2014; Supplementary Figure S3B). To further examine the functional interaction of ORA59 with RAP2.3 and group VII ERFs, we crossed ora59-1 and ORA59OE(\#5) with rap2.3-2 and erfVII lines (Supplementary Figures S3B,C). Noticeably, RAP2.3 expression was much higher in ORA59OE plants than in wild type plants (Supplementary Figures S3C), suggesting that $R A P 2.3$ expression is positively affected by ORA59. However, ORA59 expression was similar among ORA59OE and ORA59OE rap2.3 lines.

Ethylene induces the triple response in seedlings grown in the dark, featured by short, thick hypocotyl, and root, and exaggerated apical hook (Ecker, 1995). We examined whether the triple response is affected by the increased or decreased expression of ORA59 and RAP2.3 and determined the hypocotyl length of dark-grown seedlings as a measure of the 


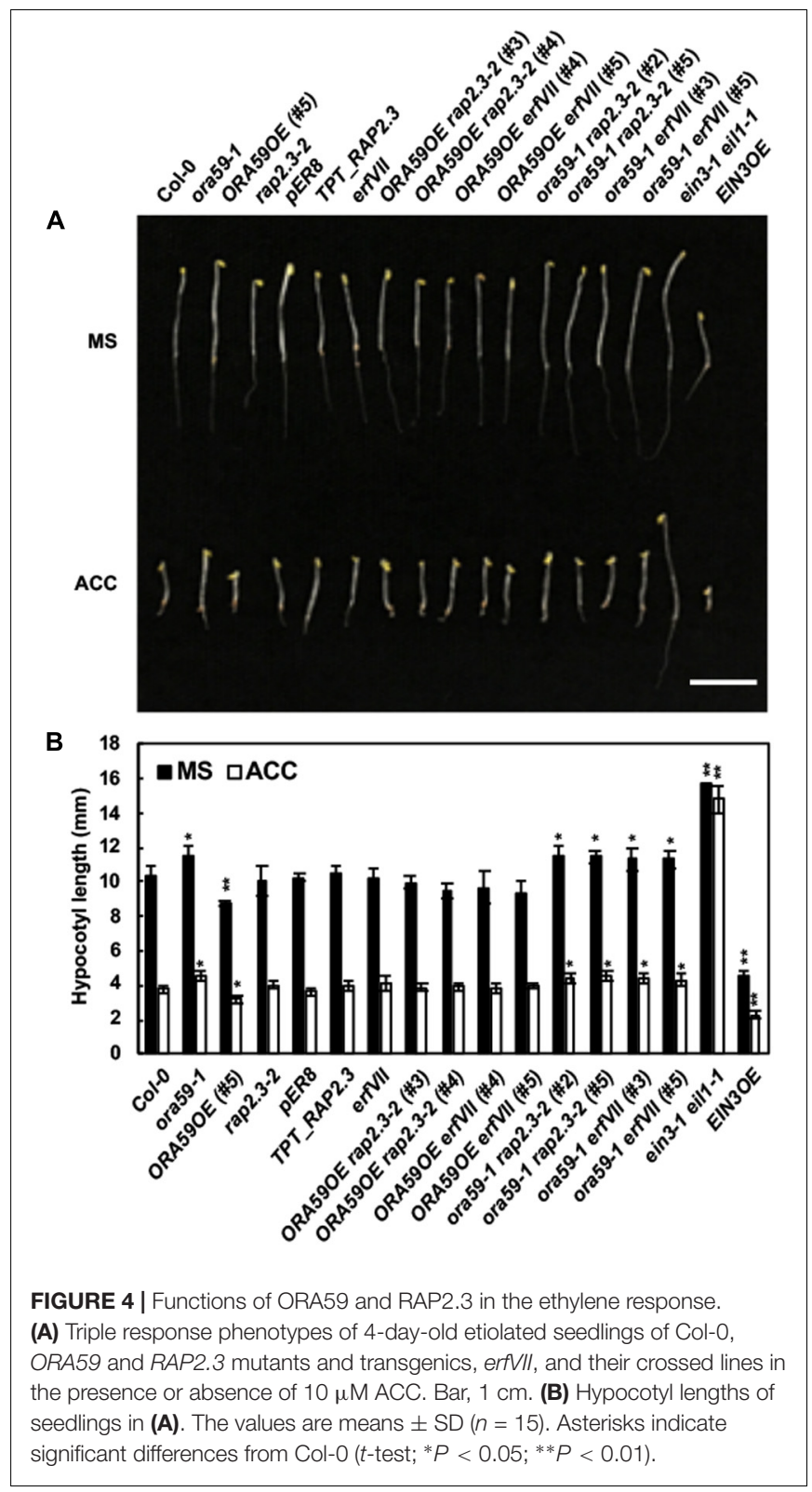

triple response. In the presence of the ethylene precursor 1aminocyclopropane-carboxylic acid (ACC), ORA59OE seedlings showed the slightly enhanced triple response with a reduction in hypocotyl elongation, and ora59 mutant showed a weaker triple response (Figure 4). Previously, apical hook formation was impaired in rap2.3 and erfVII mutants (Marín-de la Rosa et al., 2014; Abbas et al., 2015). However, hypocotyl length was not altered in TPT_RAP2.3, rap2.3, and erfVII mutant seedlings. Whereas the enhanced triple response in ORA59OE seedlings was abolished in ORA59OE rap2.3 and ORA59 erfVII crossed lines, ora59 rap2.3 and ora59 erfVII mutants displayed hypocotyl elongation similar to ora59 seedlings. These results suggest that ORA59 at least partly regulates the triple response and that this ORA59 activity depends on RAP2.3.

\section{ORA59 and RAP2.3 Control Disease Resistance}

The ethylene signaling pathway regulates resistance against necrotrophic pathogens (Kim et al., 2013). In a previous report, ORA59 was involved in resistance to the necrotrophic fungal pathogen $B$. cinerea but not to the other fungus $A$. brassicicocla in Arabidopsis (Pré et al., 2008). To further assess the roles of ORA59 and RAP2.3 in disease resistance, the prepared ORA59, RAP2.3, and ERFVII lines were challenged with the necrotrophic bacterial pathogen $P$. carotovorum. P. carotovorum causes soft rot disease in plants through secretion of cell walldegrading enzymes such as pectinases and cellulases (NormanSetterblad et al., 2000). The bacteria replicate feeding on materials released from injured cells. The severity of necrotic lesions and bacterial growth were scored and dead cells in lesions were stained with trypan blue. Necrotic disease symptoms developed in Col-0 plants, which were decreased in ORA59OE and TPT_RAP2.3 plants but increased in ora59 and rap2.3 mutants (Figures 5A-C and Supplementary Figures S4, S5). This demonstrates that ORA59 and RAP2.3 positively regulate resistance to $P$. carotovorum. Disease severity was similar in rap2.3 and erfVII plants, suggesting that RAP2.3 plays a major role in disease resistance among the group VII ERF members. When disease symptoms were compared between ORA59OE and ORA59OE rap2.3, and rap2.3 lines, the increased resistance in ORA59OE plants was compromised in ORA59OE rap2.3 plants, which showed susceptibility similar to rap 2.3 mutant. The susceptibility to $P$. carotovorum was further increased in ora59 rap2.3 and ora59 erfVII plants. PDF1.2a expression was highly induced in wild type and ORA59- and RAP2.3-overexpressing plants by $P$. carotovorum infection, but largely decreased in mutants and crossed lines with susceptible phenotypes (Figure 5D). There was no difference in PDF1.2a expression among untreated plant lines. These results suggest that ORA59 interacts with RAP2.3 in both dependent and additive manners to induce resistance to $P$. carotovorum.

\section{DISCUSSION}

Ethylene, as one of stress hormones, regulates defense responses in plants (van Loon et al., 2006; Kwon et al., 2009; Broekgaarden et al., 2015). Ethylene signaling ultimately leads to modulation of defense gene expression, which includes the action of ERFs (Müller and Munné-Bosch, 2015). ORA59 is a group IX ERF transcription factor that regulates the expression of JA- and ethylene-dependent genes including PDF1.2 by binding to the GCC-box, a cis-acting ethylene response element (Pré et al., 2008; Zarei et al., 2011). In this study, we investigated the role of ORA59 in plant defense. Y2H screening led to the identification of 12 putative ORA59 interactors, none of which have been characterized in association with ethylene and/or pathogenic responses except for RAP2.3. RAP2.3 belongs to the group VII ERF family composed of RAP2.2, RAP2.3, RAP2.12, HRE1, and HRE2 (Nakano et al., 2006). Previous studies demonstrate that the common roles of group VII ERF transcription factors are associated with plant survival under hypoxia/anoxia and 
A

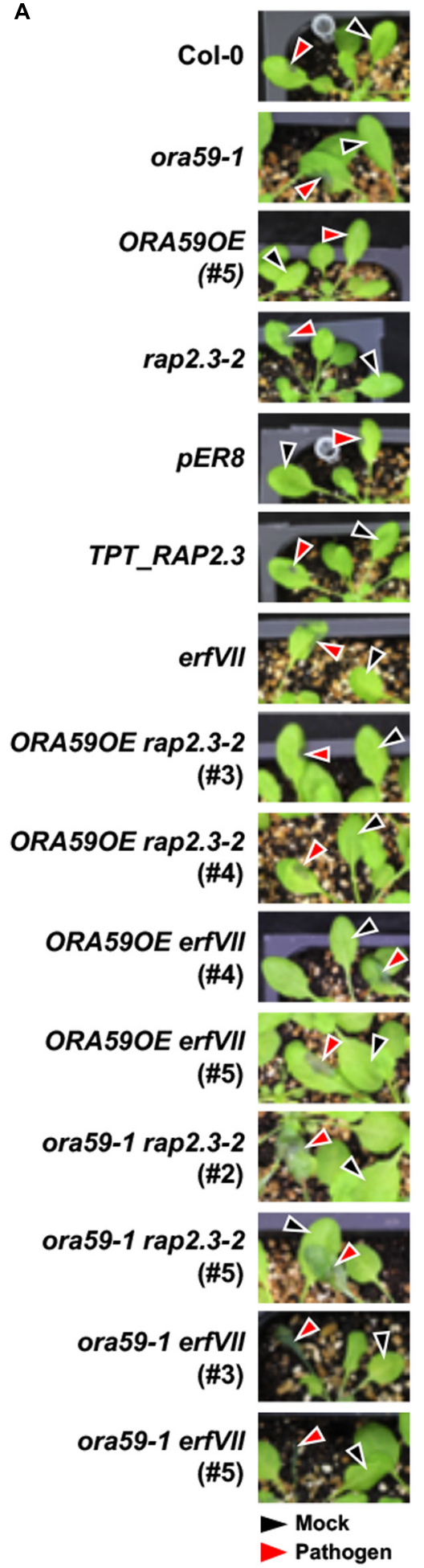

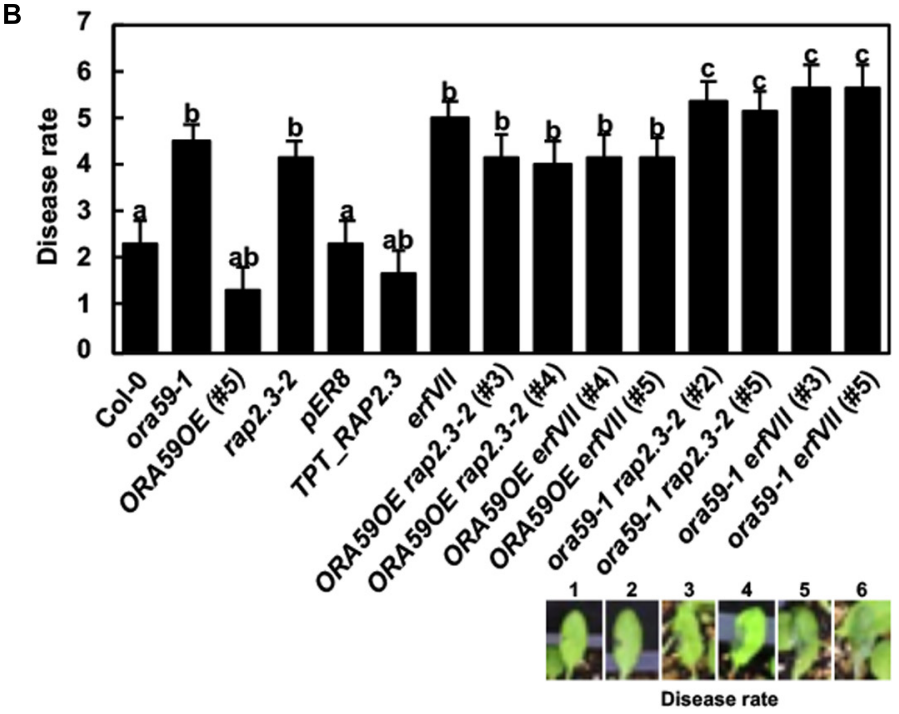

C
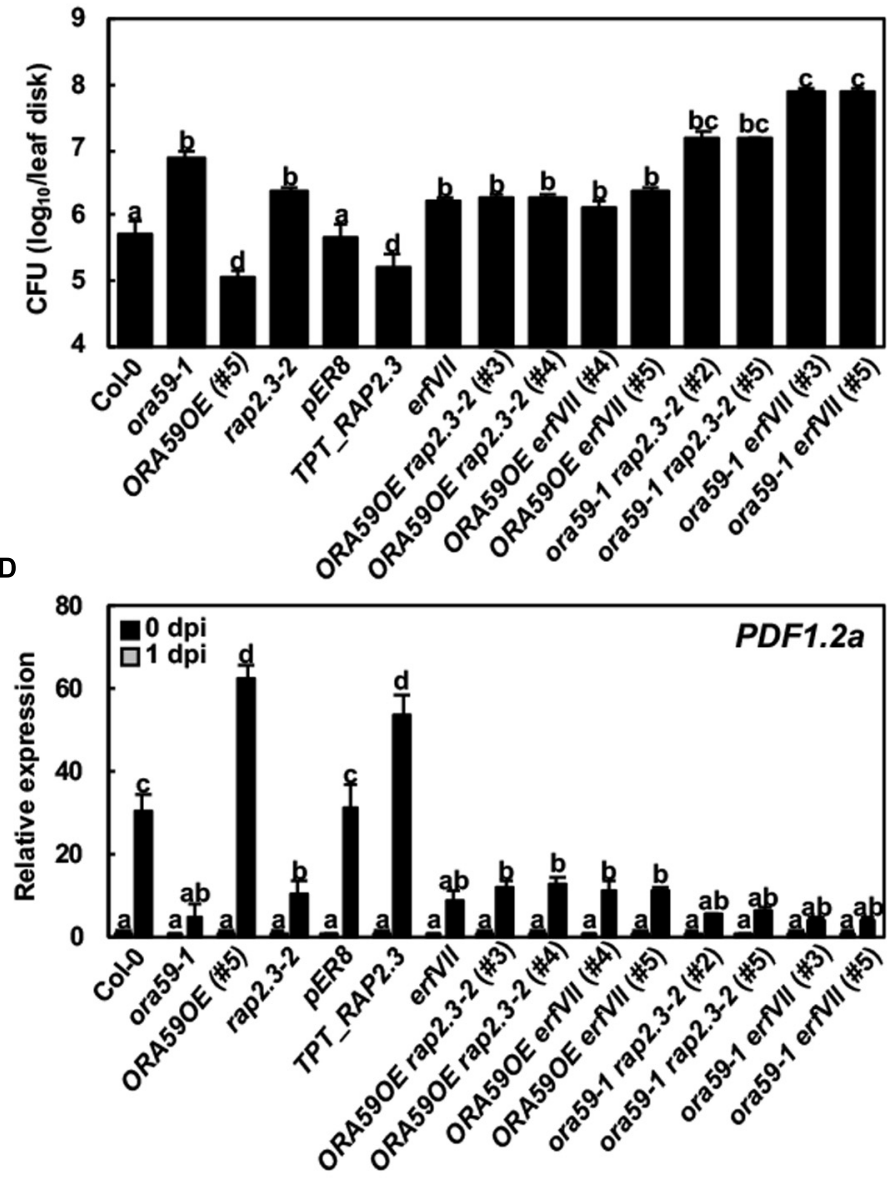

FIGURE 5 | Functions of ORA59 and RAP2.3 in resistance against $P$. carotovorum. (A) Disease symptoms in leaves inoculated with $P$. carotovorum. Inoculation sites are indicated by black arrowheads for $0.9 \% \mathrm{NaCl}$ (mock) and red arrowheads for $P$. carotovorum. (B) Disease severity estimations (1-6) in leaves of (A) were made. The values are means $\pm \operatorname{SD}(n=6)$. (C) Bacterial growth in leaves inoculated with $P$. carotovorum. The values are means \pm SD $(n=8)$. The experiment was repeated three times with similar results. (D) Expression of PDF1.2a in leaves inoculated with $P$. carotovorum. The values represent means \pm SD from three independent experiments. Five-week-old plants were treated with $10 \mu \mathrm{L}$ of $P$. carotovorum at $10^{5} \mathrm{cfu} / \mathrm{mL}$ (A,B) and $10^{4} \mathrm{cfu} / \mathrm{mL}(\mathbf{C}, \mathbf{D})$ for 1 day. Different letters indicate statistically significant difference (Tukey's HSD test; $P<0.05$ ). 
other stress conditions (Giuntoli and Perata, 2018). HRE1 and HRE2 positively affected anaerobic responses by increasing anaerobic gene expression and ethanol fermentation (Licausi et al., 2010). Overexpression of RAP2.2, RAP2.3, and RAP2.12 conferred tolerance to multiple abiotic stresses including hypoxia, whereas each single and erfVII quintuple mutants showed hypersensitive stress responses (Hinz et al., 2010; Bui et al., 2015; Papdi et al., 2015; Vicente et al., 2017). Furthermore, erfVII mutant plants had defects in the response to the gall-forming pathogen Plasmodiophora brassicae and in the stomatal immune response to the hemobiotrophic pathogen $P$. syringae pv tomato, suggesting their roles in biotic stress responses (Gravot et al., 2016; Vicente et al., 2018). According to recent findings, an increased oxygen level induces Cys oxidation and subsequent arginylation at the N-terminus of group VII ERFs, leading to proteolysis via the $\mathrm{N}$-end rule pathway (Gibbs et al., 2011; Licausi et al., 2011). These proteins accumulate under low oxygen conditions, and in this manner, act as oxygen sensors, regulating hypoxic responses. It was previously shown that RAP2.12 binds to acyl-CoA-binding proteins ACBP1/ACBP2 to protect it from the $\mathrm{N}$-end rule pathway in air (Licausi et al., 2011). This may explain our observation of RAP2.3-GFP/RFP proteins in protoplasts, as had been also demonstrated for the interaction of RAP2.3 and ACBP2/ACBP4 (Li and Chye, 2004; Li et al., 2008). CaMV 35S-driven constitutive expression of RAP2.3 may additionally contribute to RAP2.3 accumulation in protoplasts.

In this study, TPT_RAP2.3, rap2.3, and erfVII mutant seedlings showed the hypocotyl response to ethylene similar to wild type, although ORA59 required RAP2.3 for ethylene responses. On the other hand, previous studies have addressed the involvement of group VII ERFs in ethylene responses (Zhao et al., 2012; Marín-de la Rosa et al., 2014). When treated with ACC, rap2.2 rap2.12 double mutants exhibited a decrease in hypocotyl length, whereas their single mutants showed no differences in the triple response from wild type seedlings (Zhao et al., 2012). In addition, partial defects in apical hook formation were observed in rap2.3, rap2.12, and erfVII mutants in response to combined treatments of ACC and GA, but not to ACC alone (Marín-de la Rosa et al., 2014). Additional functional analyses of group VII ERF members are needed to clarify their specific and overlapping roles in ethylene responses.

A previous study demonstrates that ORA59 plays a role in disease resistance (Pré et al., 2008). ORA59-overexpressing and silenced plants were tested for responses to the necrotrophic fungal pathogens $B$. cinerea and $A$. brassicicola. Here we additionally assessed the role of ORA59 in the response to $P$. carotovorum. Previous and our data suggest that ORA59 positively regulates resistance to $B$. cinerea and $P$. carotovorum. In contrast, resistance to $A$. brassicicola was not affected in ORA59-silenced plants compared to wild type plants. The Columbia ecotype Col-0 plants are susceptible to $B$. cinerea and $P$. carotovorum, but resistant to A. brassicicola (Thomma et al., 1998, 1999; Norman-Setterblad et al., 2000; Pré et al., 2008), suggesting that ORA59 may be a component of basal immunity.

ORA59 and RAP2.3 share common features associated with ethylene responses, as demonstrated in previous reports. The expression of ORA59 and RAP2.3 was induced by ACC and

\section{Ethylene} $\perp$ ETR1

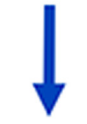
CTR1 1 EIN2 1

\section{EIN3/EIL1}

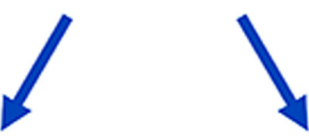

\section{ORA59 $\longleftrightarrow$ RAP2.3}

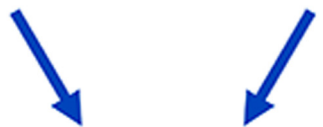

\section{Defense Response}

FIGURE 6 | A model proposing that ORA59 and RAP2.3 interact downstream of EIN2 and EIN3/EIL1 in the ethylene signaling pathway to regulate defense responses. Arrows and bars indicate positive and negative regulation, respectively, and double arrow indicates the interaction between ORA59 and RAP2.3.

ET, but greatly decreased in the ein 2-1 mutant background (Büttner and Singh, 1997; Ogawa et al., 2005; Li et al., 2008; Pré et al., 2008). Here we also showed that ET-induced ORA59 and RAP2.3 expression is abolished in ein2 and ein 3 eil1 mutants. These gene expression patterns indicate that ORA59 and RAP2.3 are located downstream of EIN2 and EIN3/EIL1 in ethylene signaling. In fact, RAP2.3 was identified as an EIN3 target in a genome-wide study of EIN3-regulated genes using chromatin immunoprecipitation followed by sequencing (Chang et al., 2013). In this study, subcellular localization of ORA59 and RAP2.3 was additionally regulated by ET. They both translocated to the nucleus in response to ET treatment. These results suggest that the transcriptional activities of ORA59 and RAP2.3 are regulated by ethylene signaling through several 
mechanisms, including gene expression, protein stability, and nuclear localization. On the other hands, hormone responses of these two genes were somewhat different. Whereas ORA59 expression was mostly specific to ET, JA, and SA, RAP2.3 responded to all the tested hormones, ET, JA, SA, ABA, and GA. This may reflect that RAP2.3 is multifunctional in regulating development and various stress responses, as previously reported. RAP2.3 overexpression conferred tolerance to hypoxia, heat, and oxidative and osmotic stresses (Ogawa et al., 2005; Papdi et al., 2015). Regarding its role in development, RAP2.3 positively regulated apical hook development, and this activity was suppressed through the interaction with the DELLA protein GIBBERELLIN INSENSITIVE, a master negative regulator in GA signaling (Marín-de la Rosa et al., 2014). ORA59 and RAP2.3 directly bound to the GCC box and their overexpression increased PDF1.2 expression (Ogawa et al., 2005; Pré et al., 2008; Zarei et al., 2011). ORA59 overexpression enhanced resistance to $B$. cinerea, and RAP2.3 expression was induced by B. cinerea infection ( $\mathrm{Li}$ et al., 2008; Pré et al., 2008). Previous studies and our data together suggest that ORA59 and RAP2.3 play common roles in ethylene-mediated defense responses (Figure 6).

In general, transcription factors form dimers with identical proteins, other members in the same family or proteins in different gene families to bind DNA and regulate gene expression. Interacting partners are selected in the context of developmental stages and stress responses, determining the specificity for target genes and leading to a specific cellular event. To date, several transcription factors that interact with ORA59 and RAP2.3 have been reported. He et al. (2017) demonstrated that ORA59 interacts with EIN3, and this interaction is required for SA-mediated reduction in ORA59 protein levels. RAP2.3 was associated with DELLA proteins (Marín-de la Rosa et al., 2014). In this case, DELLAs prevented RAP2.3 binding to the promoter of its target genes and counteracted the activity of RAP2.3 promoting apical hook closing. There was also a report about the interaction between RAP2.3 and the bZIP transcription factor TGA4, suggesting their synergistic functions

\section{REFERENCES}

Abbas, M., Berckhan, S., Rooney, D. J., Gibbs, D. J., Vicente Conde, J., Sousa Correia, C., et al. (2015). Oxygen sensing coordinates photomorphogenesis to facilitate seedling survival. Curr. Biol. 25, 1483-1488. doi: 10.1016/j.cub.2015. 03.060

Alonso, J. M., Stepanova, A. N., Solano, R., Wisman, E., Ferrari, S., Ausubel, F. M., et al. (2003). Five components of the ethylene-response pathway identified in a screen for weak ethylene-insensitive mutants in Arabidopsis. Proc. Natl. Acad. Sci. U.S.A. 100, 2992-2997. doi: 10.1073/pnas.0438070100

Asselbergh, B., De Vleesschauwer, D., and Höfte, M. (2008). Global switches and fine-tuning-ABA modulates plant pathogen defense. Mol. Plant. Microbe Interact. 21, 709-719. doi: 10.1094/MPMI-21-6-0709

Berrocal-Lobo, M., Molina, A., and Solano, R. (2002). Constitutive expression of ETHYLENE-RESPONSE-FACTOR1 in Arabidopsis confers resistance to several necrotrophic fungi. Plant J. 29, 23-32. doi: 10.1046/j.1365-313x.2002. 01191.x

Bowling, S. A., Clarke, J. D., Liu, Y., Klessig, D. F., and Dong, X. (1997). The cpr5mutant of Arabidopsis expresses both NPR1-dependent and NPR1independent resistance. Plant Cell 9, 1574-1584. doi: 10.1105/tpc.9.9.1573 to regulate gene expression during the defense response (Büttner and Singh, 1997). Our findings reveal the case of binding between members belonging to the same ERF family and imply the possibility of combinatorial interactions of ERFs for diverse gene expression regulation. Further studies of the interactions among ERFs and other types of transcription factors will enhance our understanding of the complexity of gene expression and defense responses.

\section{AUTHOR CONTRIBUTIONS}

$\mathrm{NK}$ and $\mathrm{OP}$ designed the research, analyzed the data, and wrote the article. NK and YJ performed the research.

\section{FUNDING}

This work was supported by a Korea University grant, NextGeneration BioGreen 21 Program (SSAC, PJ013202) from the Rural Development Administration, and National Research Foundation of Korea (NRF) grants (2017R1A2B4009991 and 2018R1A5A1023599, SRC) from the Korean Government (MSIP).

\section{ACKNOWLEDGMENTS}

We thank Dr. Michael Holdsworth for RAP2.3 and ERFVII seeds, Dr. Sang-Dong Yoo for ein2 seeds, and Dr. Jian-Min Zhou for EIN3OE and ein3 eil1 seeds. We also thank Myoung-Hoon Lee and Hwi Seong Jeon for technical support.

\section{SUPPLEMENTARY MATERIAL}

The Supplementary Material for this article can be found online at: https://www.frontiersin.org/articles/10.3389/fpls.2018.01675/ full\#supplementary-material

Broekgaarden, C., Caarls, L., Vos, I. A., Pieterse, C. M., and Van Wees, S. C. (2015). Ethylene: traffic controller on hormonal crossroads to defense. Plant Physiol. 169, 2371-2379. doi: 10.1104/pp.15.01020

Bui, L. T., Giuntoli, B., Kosmacz, M., Parlanti, S., and Licausi, F. (2015). Constitutively expressed ERF-VII transcription factors redundantly activate the core anaerobic response in Arabidopsis thaliana. Plant Sci. 236, 37-43. doi: 10.1016/j.plantsci.2015.03.008

Büttner, M., and Singh, K. B. (1997). Arabidopsis thaliana ethylene-responsive element binding protein (AtEBP), an ethylene-inducible, GCC box DNAbinding protein interacts with an ocs element binding protein. Proc. Natl. Acad. Sci. U.S.A. 94, 5961-5966. doi: 10.1073/pnas.94.11.5961

Caarls, L., Van der Does, D., Hickman, R., Jansen, W., Verk, M. C., Proietti, S., et al. (2017). Assessing the role of ETHYLENE RESPONSE FACTOR transcriptional repressors in salicylic acid-mediated suppression of jasmonic acid-responsive genes. Plant Cell Physiol. 58, 266-278. doi: 10.1093/pcp/pcw187

Chang, C., Kwok, S. F., Bleecker, A. B., and Meyerowitz, E. M. (1993). Arabidopsis ethylene-response gene ETR1: similarity of product to twocomponent regulators. Science 262, 539-544. doi: 10.1126/science.8211181

Chang, K. N., Zhong, S., Weirauch, M. T., Hon, G., Pelizzola, M., Li, H., et al. (2013). Temporal transcriptional response to ethylene gas drives growth 
hormone cross-regulation in Arabidopsis. eLife 2:e00675. doi: 10.7554/eLife. 00675

Chao, Q., Rothenberg, M., Solano, R., Roman, G., Terzaghi, W., and Ecker, J. R. (1997). Activation of the ethylene gas response pathway in Arabidopsis by the nuclear protein ETHYLENE-INSENSITIVE3 and related proteins. Cell 89, 1133-1144. doi: 10.1016/S0092-8674(00)80300-1

Cho, Y. H., and Yoo, S. D. (2009). Emerging complexity of ethylene signal transduction. J. Plant Biol. 52, 283-288. doi: 10.1007/s12374-009-9038-6

Clough, S. J., and Bent, A. F. (1998). Floral dip: a simplified method for Agrobacterium-mediated transformation of Arabidopsis thaliana. Plant J. 16, 735-743. doi: 10.1046/j.1365-313x.1998.00343.x

Coego, A., Brizuela, E., Castillejo, P., Ruíz, S., Koncz, C., del Pozo, J. C., et al. (2014). The TRANSPLANTA collection of Arabidopsis lines: a resource for functional analysis of transcription factors based on their conditional overexpression. Plant J. 77, 944-953. doi: 10.1111/tpj.12443

Ecker, J. R. (1995). The ethylene signal transduction pathway in plants. Science 268, 667-675. doi: 10.1126/science.7732375

Gagne, J. M., Smalle, J., Gingerich, D. J., Walker, J. M., Yoo, S. D., Yanagisawa, S., et al. (2004). Arabidopsis EIN3-binding F-box 1 and 2 form ubiquitin-protein ligases that repress ethylene action and promote growth by directing EIN3 degradation. Proc. Natl. Acad. Sci. U.S.A. 101, 6803-6808. doi: 10.1073/pnas. 0401698101

Gibbs, D. J., Lee, S. C., Isa, N. M., Gramuglia, S., Fukao, T., Bassel, G. W., et al. (2011). Homeostatic response to hypoxia is regulated by the N-end rule pathway in plants. Nature 479, 415-418. doi: 10.1038/nature10534

Giuntoli, B., and Perata, P. (2018). Group VII ethylene response factors in Arabidopsis: regulation and physiological roles. Plant Physiol. 176, 1143-1155. doi: 10.1104/pp.17.01225

Glazebrook, J. (2005). Contrasting mechanisms of defense against biotrophic and necrotrophic pathogens. Annu. Rev. Phytopathol. 43, 205-227. doi: 10.1146/ annurev.phyto.43.040204.135923

Gravot, A., Richard, G., Lime, T., Lemarié, S., Jubault, M., Lariagon, C., et al. (2016). Hypoxia response in Arabidopsis roots infected by Plasmodiophora brassicae supports the development of clubroot. BMC Plant Biol. 16:251. doi: 10.1186/s12870-016-0941-y

Guo, H., and Ecker, J. R. (2003). Plant responses to ethylene gas are mediated by SCF(EBF1/EBF2)-dependent proteolysis of EIN3 transcription factor. Cell 115, 667-677. doi: 10.1016/S0092-8674(03)00969-3

Gupta, A., Hisano, H., Hojo, Y., Matsuura, T., Ikeda, Y., Mori, I. C., et al. (2017). Global profiling of phytohormone dynamics during combined drought and pathogen stress in Arabidopsis thaliana reveals ABA and JA as major regulators. Sci. Rep. 7:4017. doi: 10.1038/s41598-017-03907-2

He, X., Jiang, J., Wang, C. Q., and Dehesh, K. (2017). ORA59 and EIN3 interaction couples jasmonate-ethylene synergistic action to antagonistic salicylic acid regulation of PDF expression. J. Integr. Plant Biol. 59, 275-287. doi: 10.1111/ jipb. 12524

Hinz, M., Wilson, I. W., Yang, J., Buerstenbinder, K., Llewellyn, D., Dennis, E. S., et al. (2010). Arabidopsis RAP2.2: an ethylene response transcription factor that is important for hypoxia survival. Plant Physiol. 153, 757-772. doi: 10.1104/pp. 110.155077

Hua, J., and Meyerowitz, E. M. (1998). Ethylene responses are negatively regulated by a receptor gene family in Arabidopsis thaliana. Cell 94, 261-271. doi: 10.1016/ S0092-8674(00)81425-7

Hua, J., Sakai, H., Nourizadeh, S., Chen, Q. G., Bleecker, A. B., Ecker, J. R., et al. (1998). EIN4 and ERS2 are members of the putative ethylene receptor gene family in Arabidopsis. Plant Cell 10, 1321-1332. doi: 10.1105/tpc.10. 8.1321

Ju, C., Yoon, G. M., Shemansky, J. M., Lin, D. Y., Ying, Z. I., Chang, J., et al. (2012). CTR1 phosphorylates the central regulator EIN2 to control ethylene hormone signaling from the ER membrane to the nucleus in Arabidopsis. Proc. Natl. Acad. Sci. U.S.A. 109, 19486-19491. doi: 10.1073/pnas.1214848109

Kieber, J. J., Rothenberg, M., Roman, G., Feldmann, K. A., and Ecker, J. R. (1993). CTR1, a negative regulator of the ethylene response pathway in Arabidopsis, encodes a member of the raf family of protein kinases. Cell 72, 427-441. doi: 10.1016/0092-8674(93)90119-B

Kim, H. G., Kwon, S. J., Jang, Y. J., Nam, M. H., Chung, J. H., Na, Y. C., et al. (2013). GDSL LIPASE1 modulates plant immunity through feedback regulation of ethylene signaling. Plant Physiol. 163, 1776-1791. doi: 10.1104/pp.113.225649
Koornneef, A., Leon-Reyes, A., Ritsema, T., Verhage, A., Den Otter, F. C., Van Loon, L. C., et al. (2008). Kinetics of salicylate-mediated suppression of jasmonate signaling reveal a role for redox modulation. Plant Physiol. 147, 1358-1368. doi: 10.1104/pp.108.121392

Kunkel, B. N., and Brooks, D. M. (2002). Cross talk between signaling pathways in pathogen defense. Curr. Opin. Plant Biol. 5, 325-331. doi: 10.1016/S13695266(02)00275-3

Kwon, S. J., Jin, H. C., Lee, S., Nam, M. H., Chung, J. H., Kwon, S. I., et al. (2009). GDSL lipase-like 1 regulates systemic resistance associated with ethylene signaling in Arabidopsis. Plant J. 58, 235-245. doi: 10.1111/j.1365-313X.2008. 03772.x

Lee, D. S., Kim, Y. C., Kwon, S. J., Ryu, C. M., and Park, O. K. (2017). The Arabidopsis cysteine-rich receptor-like kinase CRK36 regulates immunity through interaction with the cytoplasmic kinase BIK1. Front. Plant Sci. 8:1856. doi: $10.3389 /$ fpls.2017.01856

Leon-Reyes, A., Du, Y., Koornneef, A., Proietti, S., Körbes, A. P., Memelink, J., et al. (2010). Ethylene signaling renders the jasmonate response of Arabidopsis insensitive to future suppression by salicylic acid. Mol. Plant Microbe Interact. 23, 187-197. doi: 10.1094/MPMI-23-2-0187

Li, H. Y., and Chye, M. L. (2004). Arabidopsis Acyl-CoA-binding protein ACBP2 interacts with an ethylene-responsive element-binding protein, AtEBP, via its ankyrin repeats. Plant Mol. Biol. 54, 233-243. doi: 10.1023/B:PLAN. 0000028790.75090.ab

Li, H. Y., Xiao, S., and Chye, M. L. (2008). Ethylene- and pathogen-inducible Arabidopsis acyl-CoA-binding protein 4 interacts with an ethylene-responsive element binding protein. J. Exp. Bot. 59, 3997-4006. doi: 10.1093/jxb/ ern241

Licausi, F., Kosmacz, M., Weits, D. A., Giuntoli, B., Giorgi, F. M., Voesenek, L. A., et al. (2011). Oxygen sensing in plants is mediated by an N-end rule pathway for protein destabilization. Nature 479, 419-422. doi: 10.1038/nature 10536

Licausi, F., van Dongen, J. T., Giuntoli, B., Novi, G., Santaniello, A., Geigenberger, P., et al. (2010). HRE1 and HRE2, two hypoxia-inducible ethylene response factors, affect anaerobic responses in Arabidopsis thaliana. Plant J. 62, 302-315. doi: 10.1111/j.1365-313X.2010.04149.x

Lorenzo, O., Piqueras, R., Sánchez-Serrano, J. J., and Solano, R. (2003). ETHYLENE RESPONSE FACTOR1 integrates signals from ethylene and jasmonate pathways in plant defense. Plant Cell 1, 165-178. doi: 10.1105/tpc. 007468

Marín-de la Rosa, N., Sotillo, B., Miskolczi, P., Gibbs, D. J., Vicente, J., Carbonero, P., et al. (2014). Large-scale identification of gibberellin-related transcription factors defines group VII ETHYLENE RESPONSE FACTORS as functional DELLA partners. Plant Physiol. 166, 1022-1032. doi: 10.1104/pp.114. 244723

Müller, M., and Munné-Bosch, S. (2015). Ethylene response factors: a key regulatory hub in hormone and stress signaling. Plant Physiol. 169, 32-41. doi: 10.1104/pp.15.00677

Nakano, T., Suzuki, K., Fujimura, T., and Shinshi, H. (2006). Genome-wide analysis of the ERF gene family in Arabidopsis and rice. Plant Physiol. 140, 411-432. doi: 10.1104/pp.105.073783

Navarro, L., Bari, R., Achard, P., Lisón, P., Nemri, A., Harberd, N. P., et al. (2008). DELLAs control plant immune responses by modulating the balance of jasmonic acid and salicylic acid signaling. Curr. Biol. 18, 650-655. doi: 10. 1016/j.cub.2008.03.060

Norman-Setterblad, C., Vidal, S., and Palva, E. T. (2000). Interacting signal pathways control defense gene expression in Arabidopsis in response to cell wall-degrading enzymes from Erwinia carotovora. Mol. Plant Microbe Interact. 13, 430-438. doi: 10.1094/MPMI.2000.13.4.430

Ogawa, T., Pan, L., Kawai-Yamada, M., Yu, L. H., Yamamura, S., Koyama, T., et al. (2005). Functional analysis of Arabidopsis ethylene-responsive element binding protein conferring resistance to Bax and abiotic stress-induced plant cell death. Plant Physiol. 138, 1436-1445. doi: 10.1104/pp.105.063586

Papdi, C., Pérez-Salamó, I., Joseph, M. P., Giuntoli, B., Bögre, L., Koncz, C., et al. (2015). The low oxygen, oxidative and osmotic stress responses synergistically act through the ethylene response factor VII genes RAP2.12, RAP2.2 and RAP2.3. Plant J. 82, 772-784. doi: 10.1111/tpj.12848

Penninckx, I. A., Thomma, B. P., Buchala, A., Métraux, J. P., and Broekaert, W. F. (1998). Concomitant activation of jasmonate and ethylene response pathways 
is required for induction of a plant defensin gene in Arabidopsis. Plant Cell 10, 2103-2113. doi: 10.1105/tpc.10.12.2103

Pieterse, C. M., Van der Does, D., Zamioudis, C., Leon-Reyes, A., and Van Wees, S. C. (2012). Hormonal modulation of plant immunity. Annu. Rev. Cell Dev. Biol. 28, 489-521. doi: 10.1146/annurev-cellbio-092910154055

Pieterse, C. M., van Wees, S. C., Hoffland, E., van Pelt, J. A., and van Loon, L. C. (1996). Systemic resistance in Arabidopsis induced by biocontrol bacteria is independent of salicylic acid accumulation and pathogenesis-related gene expression. Plant Cell 8, 1225-1237. doi: 10.1105/tpc.8.8.1225

Potuschak, T., Lechner, E., Parmentier, Y., Yanagisawa, S., Grava, S., Koncz, C., et al. (2003). EIN3-dependent regulation of plant ethylene hormone signaling by two arabidopsis F box proteins: EBF1 and EBF2. Cell 115, 679-689. doi: 10.1016/S0092-8674(03)00968-1

Pré, M., Atallah, M., Champion, A., De Vos, M., Pieterse, C. M., and Memelink, J. (2008). The AP2/ERF domain transcription factor ORA59 integrates jasmonic acid and ethylene signals in plant defense. Plant Physiol. 147, 1347-1357. doi: $10.1104 /$ pp.108.117523

Qiao, H., Shen, Z., Huang, S. S., Schmitz, R. J., Urich, M. A., Briggs, S. P., et al. (2012). Processing and subcellular trafficking of ER-tethered EIN2 control response to ethylene gas. Science 338, 390-393. doi: 10.1126/science. 1225974

Sakai, H., Hua, J., Chen, Q. G., Chang, C., Medrano, L. J., Bleecker, A. B., et al. (1998). ETR2 is an ETR1-like gene involved in ethylene signaling in Arabidopsis. Proc. Natl. Acad. Sci. U.S.A. 95, 5812-5817. doi: 10.1073/pnas.95. 10.5812

Shan, L., He, P., Li, J., Heese, A., Peck, S. C., Nürnberger, T., et al. (2008). Bacterial effectors target the common signaling partner BAK1 to disrupt multiple MAMP receptor-signaling complexes and impede plant immunity. Cell Host Microbe 4, 17-27. doi: 10.1016/j.chom.2008.05.017

Siemens, J., Keller, I., Sarx, J., Kunz, S., Schuller, A., Nagel, W., et al. (2006). Transcriptome analysis of Arabidopsis clubroots indicate a key role for cytokinins in disease development. Mol. Plant Microbe Interact. 19, 480-494. doi: 10.1094/MPMI-19-0480

Solano, R., Stepanova, A., Chao, Q., and Ecker, J. R. (1998). Nuclear events in ethylene signaling: a transcriptional cascade mediated by ETHYLENEINSENSITIVE3 and ETHYLENE-RESPONSE-FACTOR1. Genes Dev. 12, 3703-3714. doi: 10.1101/gad.12.23.3703

Spoel, S. H., and Dong, X. (2008). Making sense of hormone crosstalk during plant immune responses. Cell Host Microbe 3, 348-351. doi: 10.1016/j.chom.2008. 05.009

Thomma, B. P., Eggermont, K., Penninckx, I. A., Mauch-Mani, B., Vogelsang, R., Cammue, B. P., et al. (1998). Separate jasmonate-dependent and salicylatedependent defense-response pathways in Arabidopsis are essential for resistance to distinct microbial pathogens. Proc. Natl. Acad. Sci. U.S.A. 95, 15107-15111. doi: 10.1073/pnas.95.25.15107

Thomma, B. P., Eggermont, K., Tierens, K. F., and Broekaert, W. F. (1999). Requirement of functional ethylene-insensitive 2 gene for efficient resistance of Arabidopsis to infection by Botrytis cinerea. Plant Physiol. 121, 1093-1102. doi: $10.1104 /$ pp.121.4.1093

Van der Does, D., Leon-Reyes, A., Koornneef, A., Van Verk, M. C., Rodenburg, N., Pauwels, L., et al. (2013). Salicylic acid suppresses jasmonic acid signaling downstream of SCFCOI1-JAZ by targeting GCC promoter motifs via transcription factor ORA59. Plant Cell 25, 744-761. doi: 10.1105/tpc.112. 108548

van Loon, L. C., Geraats, B. P., and Linthorst, H. J. (2006). Ethylene as a modulator of disease resistance in plants. Trends Plant Sci. 11, 184-191. doi: 10.1016/j. tplants.2006.02.005

Vicente, J., Mendiondo, G. M., Movahedi, M., Peirats-Llobet, M., Juan, Y. T., Shen, Y. Y., et al. (2017). The Cys-Arg/N-end rule pathway is a general sensor of abiotic stress in flowering plants. Curr. Biol. 27, 3183-3190. doi: 10.1016/j.cub. 2017.09.006

Vicente, J., Mendiondo, G. M., Pauwels, J., Pastor, V., Izquierdo, Y., Naumann, C., et al. (2018). Distinct branches of the N-end rule pathway modulate the plant immune response. New Phytol. doi: 10.1111/nph.15387 [Epub ahead of print].

Wang, D., Pajerowska-Mukhtar, K., Culler, A. H., and Dong, X. (2007). Salicylic acid inhibits pathogen growth in plants through repression of the auxin signaling pathway. Curr. Biol. 17, 1784-1790. doi: 10.1016/j.cub.2007.09.025

Wang, K. L., Li, H., and Ecker, J. R. (2002). Ethylene biosynthesis and signaling networks. Plant Cell 14(Suppl.), S131-S151. doi: 10.1105/tpc.001768

Wen, X., Zhang, C., Ji, Y., Zhao, Q., He, W., An, F., et al. (2012). Activation of ethylene signaling is mediated by nuclear translocation of the cleaved EIN2 carboxyl terminus. Cell Res. 22, 1613-1616. doi: 10.1038/cr.2012.145

Yoo, S. D., Cho, Y. H., Tena, G., Xiong, Y., and Sheen, J. (2008). Dual control of nuclear EIN3 by bifurcate MAPK cascades in C2H4 signalling. Nature 451, 789-795. doi: 10.1038/nature06543

Zarei, A., Körbes, A. P., Younessi, P., Montiel, G., Champion, A., and Memelink, J. (2011). Two GCC boxes and AP2/ERF-domain transcription factor ORA59 in jasmonate/ethylene-mediated activation of the PDF1.2 promoter in Arabidopsis. Plant Mol. Biol. 75, 321-331. doi: 10.1007/s11103010-9728-y

Zhao, Y., Wei, T., Yin, K. Q., Chen, Z., Gu, H., Qu, L. J., et al. (2012). Arabidopsis RAP2.2 plays an important role in plant resistance to Botrytis cinerea and ethylene responses. New Phytol. 195, 450-460. doi: 10.1111/j.1469-8137.2012. 04160.x

Conflict of Interest Statement: The authors declare that the research was conducted in the absence of any commercial or financial relationships that could be construed as a potential conflict of interest.

Copyright (C) 2018 Kim, Jang and Park. This is an open-access article distributed under the terms of the Creative Commons Attribution License (CC BY). The use, distribution or reproduction in other forums is permitted, provided the original author(s) and the copyright owner(s) are credited and that the original publication in this journal is cited, in accordance with accepted academic practice. No use, distribution or reproduction is permitted which does not comply with these terms. 